\title{
Paradoxical resistance to diet-induced obesity in UCP1-deficient mice
}

\author{
Xiaotuan Liu, Martin Rossmeisl, Jennifer McClaine, and Leslie P. Kozak \\ Pennington Biomedical Research Center, Baton Rouge, Louisiana, USA
}

\begin{abstract}
The availability of mice lacking the mitochondrial uncoupling protein UCP1, has provided an opportunity to analyze the relationship between the capacity for energy expenditure and the development of obesity in response to a high-fat, high-sucrose diet. Congenic UCP1-deficient mice on a C57BL/6J genetic background show a temperature-dependent resistance to diet-induced obesity when compared with wild-type mice. This resistance, which occurs at $20^{\circ} \mathrm{C}$, is quickly reversed when the ambient temperature is increased to $27^{\circ} \mathrm{C}$. At $20^{\circ} \mathrm{C}$, total oxygen consumption and physical activity of mutant and wild-type mice are indistinguishable; however, body temperature is higher in UCP1-deficient mice by $0.1-0.3^{\circ} \mathrm{C}$, and respiratory quotient is slightly reduced. A reduced respiratory quotient, together with elevated $\beta$-hydroxybutyrate and reduced plasma fatty acid levels, suggests that the mutants oxidize a greater proportion of fat than wild-type mice, and that this possibly accounts for the resistance to diet-induced obesity. Although shivering is one alternative mechanism of thermogenesis that is probably used in UCP1-deficient mice, whether there are others remains to be determined. Nevertheless, our study underscores the paradox that elimination of the major thermogenic mechanism in the animal reduces rather than increases metabolic efficiency. We propose that in the absence of nonshivering thermogenesis, alternative, calorically more costly pathways of metabolism must be used to maintain body temperature.
\end{abstract}

J. Clin. Invest. 111:399-407 (2003). doi:10.1172/JCI200315737.

\section{Introduction}

The idea that maintaining energy homeostasis during episodes of excessive caloric intake could be achieved by activation of nonshivering thermogenesis in brown fat was first introduced by Rothwell and Stock (1). Activation of nonshivering thermogenesis following consumption of a cafeteria diet by rats was initially evident by increased oxygen consumption upon adrenergic stimulation $(1,2)$. Consistent with the metabolic responses, it was subsequently shown by several research groups that induction of mitochondrial uncoupling protein 1 gene $(U c p 1)$ expression also occurs in animals fed a cafeteria diet (3). Since an intact $U c p 1$ gene is essential for nonshivering thermogenesis $(4,5)$, and genetic and pharmacological manipulations that increase Ucp 1 expression empower the animal to resist experimentally induced obesity (6-12), the effectiveness of UCP1-

Received for publication April 18, 2002, and accepted in revised form December 11, 2002.

Address correspondence to: Leslie P. Kozak, Pennington Biomedical Research Center, 6400 Perkins Road, Baton Rouge, Louisiana 70808, USA. Phone: (225) 763-2771;

Fax: (225) 763-3030; E-mail: kozaklp@pbrc.edu.

Martin Rossmeisl's present address is: Institute for Physiology, Czech Academy of Sciences, Videnska, Prague, Czech Republic.

Conflict of interest: Part of this work has been supported by a grant from Pfizer Inc.

Nonstandard abbreviations used: uncoupling protein 1 (UCP1); 57BL/6J (B6); 129/SvPas (129); respiratory quotient (RQ); percent relative cumulative frequency $(\mathrm{PRCF})$; triiodothyronine (T3); thyroxine (T4); type II 5'-T4 deiodinase (5'-D-II); glycerol-3phosphate dehydrogenase (GPDH); mitochondrial glycerol-3phosphate dehydrogenase (mGPDH). mediated thermogenesis has been convincingly established in rodents. The mechanism by which nonshivering thermogenesis can be activated to reduce obesity in adult humans remains to be established.

If increased Ucp1 expression prevents or reduces excessive adiposity in mice, then it follows that reductions in Ucp1 expression should increase adiposity. However, the absence of an increase in obesity in UCP1deficient compared with wild-type mice fed a high-fat diet (4) was unexpected in view of the obesity that developed in Ucp1-DTA (brown adipose tissue-ablated) mice (13). It has since been reported that Ucp1DTA transgenic mice still have $50 \%$ of levels of Ucp 1 mRNA in their brown fat and, consequently, retain a significant number of brown adipocytes (14). Their obesity likely comes from hyperphagia that is caused by their extreme resistance to leptin (15). Another mouse model of more extreme brown fat deficiency, caused by constitutive overexpression of UCP1 to toxic levels, is cold-sensitive, like UCP1-deficient mice, and resistant to diet-induced obesity (16). Accordingly, at the present time there is no evidence that either brown adipocyte deficiency or UCP1 deficiency increases susceptibility to obesity. To determine whether the absence of UCP1-mediated thermogenesis has a phenotype related to the regulation of body weight, it was necessary to construct C57BL/6J (B6) congenic mice carrying the Ucp 1 mutant allele. The initial observations on the absence of increased obesity in UCP1-deficient mice were made on Ucp1-targeted mice on an undefined mixed genetic background derived from the B6 and $129 /$ SvPas (129) strains. The interpretation of the 
effects of UCP1 deficiency on this background is complicated by the fact that, whereas $\mathrm{B} 6$ mice become obese on a high-fat diet (17), the 129 strain is resistant to the development of obesity (18). Accordingly, we have constructed congenic lines of Ucp1-targeted mice on B6 and 129 genetic backgrounds to determine why UCP1 deficiency does not cause obesity in animals. The profound effects of genetic background on the ability of Ucp1-targeted mice to tolerate exposure to cold have recently been demonstrated (19). In this paper we show that congenic B6.UCP1-deficient mice, fed a high-fat diet, are more resistant to diet-induced obesity than are the wild-type controls. We propose that UCP1-deficient mice have a less efficient energy metabolism that is dependent on increased oxidation of fat, compared with the wild-type controls. These results with UCP1deficient mice illustrate the economy of brown adipocyte-dependent nonshivering thermogenesis for controlling body temperature and suggest that inactivation of this mechanism forces the animal to employ alternative thermogenic mechanisms that are metabolically more expensive. These mechanisms remains to be identified.

\section{Methods}

Animals. Congenic lines of $U c p 1^{-/-}$mice were generated by backcross matings of heterozygous $(+/-)$ mice on a mixed 129/SvPas and C57BL/6J background with 129/SvImJ and C57BL/6J mice as described (19). In this study all wild-type mice are C57BL/6J and are referred to as $U c p 1^{+/+}$and all $U c p 1$ mutant mice are on the C57BL/6J background and are referred to as $U c p 1^{-/}$. UCP1-deficient mice require the breeding room to be maintained at $27^{\circ} \mathrm{C}$; otherwise the $U c p 1^{-/-}$ progeny die within the first day after birth. Mice were routinely housed at $27^{\circ} \mathrm{C}$ on a 12-hour light-dark cycle and fed standard chow (no. 5053; PMI Lab Diet, St. Louis, Missouri, USA) until the start of an experiment. With one exception (see Table 4), all experiments were performed with 2-month-old male congenic $U c p 1^{-/-}$ mice, and $U c p 1^{+/+}$mice as controls. Mice were fed either a high-fat diet in which $58 \%, 26 \%$, and $16 \%$ of the calories came from fat, carbohydrate, and protein, respectively (catalog no. D12331; Research Diets Inc., New Brunswick, New Jersey, USA), or a low-fat chow diet with a caloric composition of $23.5 \%$ protein, $12 \%$ fat, and $64.5 \%$ carbohydrate (no. 5053; PicoLab Inc.).

Indirect calorimetry. Energy expenditure $\left(\mathrm{VO}_{2}\right)$ and respiratory quotient (RQ) were measured by an Oxymax indirect calorimeter (Columbus Instruments, Columbus, Ohio, USA) with an air flow of $0.75 \mathrm{l} / \mathrm{min}$. RQ is the ratio of the volume of $\mathrm{CO}_{2}$ produced to the volume of $\mathrm{O}_{2}$ consumed. $\mathrm{VO}_{2}$ is expressed as the volume of $\mathrm{O}_{2}$ consumed per kilogram body weight per hour. After 1 hour to allow for adaptation to the metabolic chamber, $\mathrm{VO}_{2}$ was measured in individual mice at 15 -minute intervals for 24 hours under the same environmental temperature as that of the feeding experiment. Mice had free access to food and water during the measure- ment. Data on RQs was analyzed as percent relative cumulative frequency (PRCF), a method developed by M. Riachi et al. (manuscript submitted for publication) to facilitate interpretation of large data sets from indirect calorimetry. Rather than present chronological RQ data, we show the PRCF for all RQ values for the 24hour period for the eight mice in each group. Each curve is derived from 640 measurements from an experimental group of eight mice. Raw data are then sorted from smallest to highest values. In an adjacent column the frequency of each RQ increment is then calculated. The frequency of each data point is then added to the frequency of the next increment in the sequence. This results in what is known as a cumulative frequency sequence. To address the slight differences in the number of data points collected between mouse groups and to facilitate comparisons of data sets from experiment to experiment, cumulative frequency values are then converted to percent relative cumulative frequencies. This is achieved by dividing the individual cumulative frequencies at each $\mathrm{VO}_{2}$ increment by the sum of the frequencies and then multiplying by 100 . This final column is thus the PRCF sequence. The resulting curves resemble dose-response curves as used in pharmacology and provide a sensitive indicator of slight shifts to lower or higher RQ.

Biotelemetry. Core body temperature and physical activity were continuously monitored in conscious, unrestrained mice with a VitalView Data Acquisition System (Mini Mitter Co., Sunriver, Oregon, USA). Briefly, each mouse was anesthetized, and a temperature-sensitive transmitter (PDT-4000) (Mini Mitter Co.) was implanted intra-abdominally. Mice were allowed to recover for a minimum of 7 days after implantation. The signals emitted by the transmitter (ER-4000) (Mini Mitter Co.) were received and converted into temperature and activity by VitalView software. Core body temperature and physical activity were monitored at a rate of 30 measurements per hour.

Blood chemistries. Blood was collected from mice, fed or fasted overnight, by tail bleeding in the morning two hours after the lights came on. Blood glucose was assayed with a glucometer (One Touch; LifeScan Inc., Milpitas, California, USA). Enzymatic assay kits were used for determination of plasma FFAs, $\beta$-hydroxybutyrate (Wako Chemicals USA Inc., Richmond, Virginia, USA), and total triglycerides (Sigma-Aldrich, St. Louis, Missouri, USA). RIA kits were used for measurements of serum triiodothyronine (T3) and thyroxine (T4) (Diagnostic Products Corp., Los Angeles, California, USA).

Histology. Subcutaneous and intra-abdominal fat pads were fixed in Bouin's solution and embedded in paraffin, and sections were stained with $\mathrm{H} \& \mathrm{E}$.

Real-time quantitative RT-PCR. Total RNA was isolated from brown fat, inguinal fat, liver, and muscle using TRI Reagent (Molecular Research Center Inc., Cincinnati, Ohio, USA). The mRNA levels of type II deiodinase and PPAR $\alpha$ were analyzed by real-time RT-PCR in the ABI Prism 7900 HT Sequence Detec- 


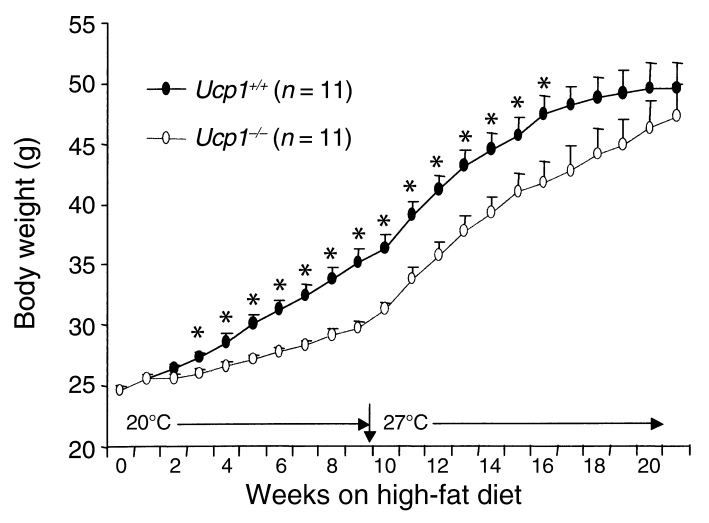

Figure 1

Effect of reduced ambient temperature on development of obesity in male 2-month-old $U c p 1^{+/+}$mice (filled symbols) and $U c p 1^{-/-}$mice (open symbols) fed a high-fat diet. ${ }^{*} P<0.05$.

tion System (Applied Biosystems, Foster City, California, USA) with cyclophilin mRNA as an internal control. The primers and probes were as follows: type II deiodinase, forward, $5^{\prime}$-GCTGCGCTGTGTCTGGAA3'; reverse, 5'-TGGAATTGGGATCATCTTCAC-3'; probe, $5^{\prime}$-AGCTTCCTCCTAGATGCCTACAAACAGGTTAAACTG$3^{\prime}$; PPAR $\alpha$, forward, 5'-GACAAGGCCTCAGGGTACCA-3'; reverse, 5'-GCCGAATAGTTCGCCGAAA-3'; probe, 5'AGCCCTTACAGCCTTCACATGGGTGA-3'; cyclophilin, forward, 5'-GGTGGAGAGCACCAAGACAGA-3'; reverse, 5'-GCCGGAGTCGACAATGATG-3'; probe, 5'-AGCCGGGACAAGCCACTGAAGGAT-3'

Statistical analysis. Values are reported as means \pm SEM and were calculated using StatView (version 4.5; Abacus Concepts Inc., San Francisco, California, USA). Statistical significance of the difference in mean values between groups was determined by unpaired $t$ test. Comparisons between groups were determined by Fisher's protected least-significant difference. Differences were considered significant at $P<0.05$.

\section{Results}

Diet-induced obesity on a congenic background. Both $U c p 1^{-/-}$ and $U c p 1^{+/+}$progeny were maintained at $27^{\circ} \mathrm{C}$ following weaning, during which time they were fed a chow diet with $11 \mathrm{kcal} \%$ fat. At 2 months of age, $U c p 1^{+/+}$and $\mathrm{Ucp}^{-1-}$ mice were transferred to a room maintained at $20^{\circ} \mathrm{C}$, housed individually, and fed a high-fat, highsucrose diet, and both food intake and body weight were measured weekly. At the beginning of the feeding experiment at 2 months of age, body weights were indistinguishable between the two genotypes, and they were not statistically different until the second week, when it became apparent that the wild-type mice were gaining weight at a faster rate than the UCP1-deficient mice (Figure 1). This difference in body weight continued to increase during subsequent weeks, until the ninth week, at which time the $U_{c p} 1^{+/+}$mice gained $12 \mathrm{~g}$ whereas the $U c p 1^{-/-}$mice gained only $4 \mathrm{~g}$. At the ninth week, the room temperature was adjusted back to $27^{\circ} \mathrm{C}$, while the diet and all other treatments remained the same. Under these conditions, both $U c p 1^{+/+}$and $U c p 1^{-/-}$mice began to gain weight at a similar increased rate. The body weights began to reach a plateau first in the $U c p 1^{+/+}$and then in the $U c p 1^{-/-}$mice. By the 17 th week, the differences in body weights between the two groups were statistically insignificant (Figure 1). To determine how the reduction in body weight affected fat depots, a second feeding experiment was performed that was terminated after 8 weeks on a high-fat diet at $20^{\circ} \mathrm{C}$. The body weight gain was significantly reduced in $U c p 1^{-/-}$mice, as were the weights of all white fat depots (Table 1). Brown fat and liver weights were not significantly different. Throughout this feeding experiment, no differences in food intake between the mutant and wild-type mice were detected (cumulative energy intake in kilocalories over the 8-week period was $827.5 \pm 86.5$ for $U c p 1^{+/+}$and $807.1 \pm 42.3$ for $U c p 1^{-/-} ; P=0.58$ ), indicating that the differences in body weight could not be accounted for by differences in energy intake.

Energy expenditure by indirect calorimetry. Mice with the UCP1-deficient phenotype gain less weight than wildtype mice when the ambient temperature is lowered, without a change in food intake. We hypothesized that a UCP1-independent thermogenic mechanism can be activated to maintain normal body temperature and that it does so by increased utilization of excessive lipid stores. To test this hypothesis, we first used indirect calorimetry to compare energy expenditure in wild-type and knockout mice. The experiment, described in Table 2 , has attempted to determine whether differences in oxygen consumption and RQ could be detected as diet and ambient temperature was varied. In the first phase of the experiment, 2-month-old mutant and wild-type mice were fed a chow diet for 2 weeks at $27^{\circ} \mathrm{C}$. Determinations of oxygen consumption and RQ over a 24hour period at the end of this phase showed that oxy-

\section{Table 1}

Body weight and adiposity of $U c p 1^{-/-}$and $U_{c p} 1^{+/+}$mice fed a $58 \mathrm{kcal} \%$ high-fat diet for 8 weeks at $20^{\circ} \mathrm{C}$

\begin{tabular}{lccc}
\hline & $\begin{array}{c}U c p 1^{+/+} \\
(n=10)\end{array}$ & $\begin{array}{c}U c p 1^{-/-} \\
(n=9)\end{array}$ & $\begin{array}{c}P \text { value } \\
-/- \text { vs. }+/+\end{array}$ \\
& & & \\
Body weight (g) & $28.9 \pm 0.6$ & $28.4 \pm 0.5$ & 0.524 \\
$\quad$ Initial & $34.5 \pm 1.2$ & $31.1 \pm 1.1$ & 0.060 \\
$\quad$ Final & $5.6 \pm 0.7$ & $2.7 \pm 0.8^{\mathrm{A}}$ & 0.015 \\
$\quad$ Change & $0.15 \pm 0.01$ & $0.13 \pm 0.01$ & 0.342 \\
Brown fat (g) & $0.33 \pm 0.05$ & $0.18 \pm 0.03^{\mathrm{A}}$ & 0.016 \\
Retroperitoneal fat (g) & $0.71 \pm 0.06$ & $0.54 \pm 0.05$ & 0.055 \\
Inguinal fat (g) & $1.17 \pm 0.16$ & $0.67 \pm 0.10^{\mathrm{A}}$ & 0.021 \\
Epididymal fat (g) & $0.43 \pm 0.06$ & $0.33 \pm 0.04$ & 0.221 \\
Mesenteric fat (g) & $2.64 \pm 0.33$ & $1.72 \pm 0.22^{\mathrm{A}}$ & 0.035 \\
Total fat depots (g) & $7.44 \pm 0.63$ & $5.40 \pm 0.48^{\mathrm{A}}$ & 0.021 \\
Adiposity index & & & \\
(\% body weight) & $1.26 \pm 0.06$ & $1.29 \pm 0.05$ & 0.735 \\
Liver (g) & & &
\end{tabular}

Male mice at 2 months of age, reared at $27^{\circ} \mathrm{C}$, were individually housed in body cages and fed a high-fat diet. After 8 weeks, mice were sacrificed and tissue weights were determined. ASignificant differences between $U_{c p} 1^{+/+}$and $U c p 1^{-1-}$ mice at $P<0.05$. 
Table 2

$\mathrm{VO}_{2}$ and $\mathrm{RQ}$ of $U_{c p} 1^{-/-}$and $U c p 1^{+/+}$mice during feeding experiment

\begin{tabular}{|c|c|c|c|}
\hline \multicolumn{4}{|c|}{$\mathrm{VO}_{2}(\mathrm{ml} / \mathrm{kg} / \mathrm{h})$} \\
\hline \multicolumn{4}{|c|}{$27^{\circ} \mathrm{C}$, chow ( 2 weeks) } \\
\hline $\begin{array}{l}U_{c p} 1^{+/+} \\
U c p 1^{-/-}\end{array}$ & $\begin{array}{l}2,790 \pm 49 \\
2,756 \pm 89\end{array}$ & $\begin{array}{l}3,071 \pm 65 \\
3,002 \pm 92\end{array}$ & $\begin{array}{l}2,509 \pm 43 \\
2,510 \pm 95\end{array}$ \\
\hline \multicolumn{4}{|c|}{$27^{\circ} \mathrm{C}$, high-fat (2 weeks) } \\
\hline $\begin{array}{l}U c p 1^{+/+} \\
U c p 1^{-/-}\end{array}$ & $\begin{array}{l}2,985 \pm 68 \\
2,736 \pm 73\end{array}$ & $\begin{array}{l}3,189 \pm 66 \\
2,952 \pm 93\end{array}$ & $\begin{array}{l}2,782 \pm 79 \\
2,521 \pm 69\end{array}$ \\
\hline \multicolumn{4}{|c|}{$20^{\circ} \mathrm{C}$, high-fat ( 2 weeks) } \\
\hline $\begin{array}{l}U_{c p 11^{++}} \\
U_{c p} 1^{-/-}\end{array}$ & $\begin{array}{l}4,151 \pm 127^{A, B} \\
3,877 \pm 102^{A, B}\end{array}$ & $\begin{array}{l}4,442 \pm 117^{\mathrm{A}, \mathrm{B}} \\
4,079 \pm 107^{\mathrm{A}, \mathrm{B}}\end{array}$ & $\begin{array}{l}3,868 \pm 147^{A, B} \\
3,675 \pm 101^{A, B}\end{array}$ \\
\hline \multicolumn{4}{|c|}{$20^{\circ} \mathrm{C}$, high-fat (17 weeks) } \\
\hline $\begin{array}{l}U c p 1^{+/+} \\
U c p 1^{-/-}\end{array}$ & $\begin{array}{l}4,414 \pm 307^{A, B} \\
4,157 \pm 293^{A, B}\end{array}$ & $\begin{array}{l}4,608 \pm 329^{\mathrm{A}, \mathrm{B}} \\
4,323 \pm 309^{\mathrm{A}, \mathrm{B}}\end{array}$ & $\begin{array}{l}4,204 \pm 280^{A, B} \\
3,988 \pm 278^{A, B}\end{array}$ \\
\hline \multicolumn{4}{|l|}{ RQ } \\
\hline \multicolumn{4}{|c|}{$27^{\circ} \mathrm{C}$, chow ( 2 weeks) } \\
\hline $\begin{array}{l}U_{c p 1^{+/+}} \\
U_{c p} 1^{-/-}\end{array}$ & $\begin{array}{l}0.92 \pm 0.003 \\
0.92 \pm 0.010\end{array}$ & $\begin{array}{l}0.95 \pm 0.005 \\
0.94 \pm 0.008\end{array}$ & $\begin{array}{l}0.90 \pm 0.004 \\
0.91 \pm 0.014\end{array}$ \\
\hline \multicolumn{4}{|c|}{$27^{\circ} \mathrm{C}$, high-fat ( 2 weeks) } \\
\hline $\begin{array}{l}U_{c p} 1^{+/+} \\
U c p 1^{-/-}\end{array}$ & $\begin{array}{l}0.77 \pm 0.013^{A} \\
0.78 \pm 0.005^{A}\end{array}$ & $\begin{array}{l}0.77 \pm 0.015^{A} \\
0.79 \pm 0.006^{A}\end{array}$ & $\begin{array}{l}0.77 \pm 0.011^{\mathrm{A}} \\
0.78 \pm 0.005^{\mathrm{A}}\end{array}$ \\
\hline \multicolumn{4}{|c|}{$20^{\circ} \mathrm{C}$, high-fat ( 2 weeks) } \\
\hline $\begin{array}{l}U_{c p} 1^{+/+} \\
U_{c p} 1^{-/-}\end{array}$ & $\begin{array}{l}0.77 \pm 0.008^{A} \\
0.77 \pm 0.006^{A}\end{array}$ & $\begin{array}{l}0.77 \pm 0.005^{A} \\
0.78 \pm 0.006^{A}\end{array}$ & $\begin{array}{l}0.77 \pm 0.007^{\mathrm{A}} \\
0.77 \pm 0.006^{\mathrm{A}}\end{array}$ \\
\hline \multicolumn{4}{|c|}{$20^{\circ} \mathrm{C}$, high-fat (17 weeks) } \\
\hline $\begin{array}{l}U_{c p} 1^{+/+} \\
U_{c p} 1^{-/-}\end{array}$ & $\begin{array}{l}0.79 \pm 0.010^{\mathrm{A}} \\
0.78 \pm 0.011^{\mathrm{A}}\end{array}$ & $\begin{array}{l}0.79 \pm 0.012^{\mathrm{A}} \\
0.78 \pm 0.011^{\mathrm{A}}\end{array}$ & $\begin{array}{l}0.80 \pm 0.008^{A} \\
0.78 \pm 0.012^{A}\end{array}$ \\
\hline
\end{tabular}

$\mathrm{VO}_{2}$ and $\mathrm{RQ}$ were measured in 2-month-old male mice fed standard chow diet and reared at $27^{\circ} \mathrm{C}$. The mice were then placed onto a high-fat diet for 2 weeks while temperature was maintained at $27^{\circ} \mathrm{C}$ and the $\mathrm{VO}_{2}$ and $\mathrm{RQ}$ measurements were repeated. Mice were then transferred to $20^{\circ} \mathrm{C}$ and maintained on a high-fat diet. $\mathrm{VO}_{2}$ and $\mathrm{RQ}$ measurements were performed on the mice at 2 weeks and 17 weeks during this final regimen. Significant differences between treatments within the same genotype are as follows: ${ }^{A} P<0.05 \mathrm{com}-$ pared with the group of 2-month-old mice fed chow at $27^{\circ} \mathrm{C} ;{ }^{\mathrm{B} P}<0.05 \mathrm{com}$ pared with the group of mice fed high-fat diet at $27^{\circ} \mathrm{C}$.

gen consumption and RQ were higher during the dark period; however, no differences were detected between the mutant and wild-type mice (Table 2). In the second phase, the same mice were fed a high-fat diet, and the ambient temperature remained at $27^{\circ} \mathrm{C}$. The pattern of oxygen consumption remained the same as in the first phase, but the RQ dropped from 0.94 to 0.78 , consistent with the increase in fat utilization upon being fed a high-fat diet. No differences were detected between mutant and wild-type mice. In the third phase, mice continued on the high-fat diet, but the temperature was reduced to $20^{\circ} \mathrm{C}$. Under these conditions, oxygen consumption increased by $40 \%$, but the RQ remained unchanged. No differences were detected between mutant and wild-type mice. In a second experiment, a separate group of mice was maintained at $20^{\circ} \mathrm{C}$ while being fed a high-fat diet for 17 weeks. Oxygen consumption was high in these mice, as in the first experiment; the overall mean of the RQ remained at 0.78 , and no significant differences could be detected between the mutant and the wild-type mice. Accordingly, when the data were averaged over a 12 - to 24 -hour period, no significant differences between $U c p 1^{+/+}$and $U c p 1^{-/-}$mice could be detected in oxygen consumption or RQ under conditions that caused an attenuation in the accumulation of fat (Figure 1).

In some experiments, reduced RQ has been observed in UCP1-deficient mice, but these results have not been consistently reproduced. Accordingly, we have used a new method for evaluating data on indirect calorimetry that is based upon a graph of the PRCF of individual values for the RQ (Riachi et al., manuscript submitted for publication). A comparison of the PRCF in mice maintained at $27^{\circ} \mathrm{C}$ and fed either a low-fat or a high-fat diet serves to illustrate the large shift to the right toward higher RQ values as predicted from the difference in 24-hour mean RQ depicted in Table 2. Although the averaged 24-hour RQ data showed no difference in the RQ between $U c p 1^{+/+}$and $U c p 1^{-/-}$fed the same diet at the same ambient temperature (Table 2), a consistent leftward shift in the PRCF of RQ toward lower RQ values is observed in $U c p 1^{-/-}$mice fed a highfat diet at either $27^{\circ} \mathrm{C}$ or $20^{\circ} \mathrm{C}$. There is no evidence of a shift toward lower RQ in $U c p 1^{-/-}$mice fed a low-fat chow diet (Figure 2a). The data indicate that a higher frequency of lower RQ values was present in the Ucp $1^{-/-}$ mice. The data also suggest that lower RQ in $U c p 1^{-/-}$

a

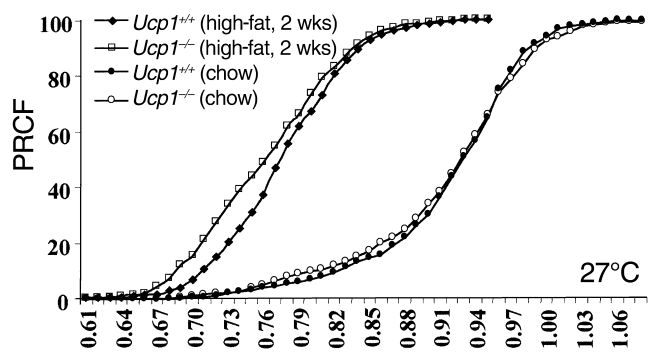

b

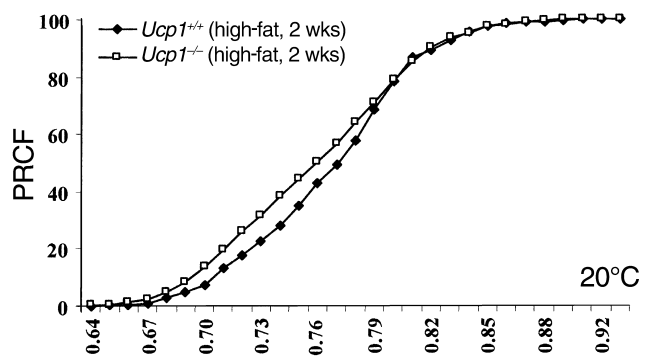

c

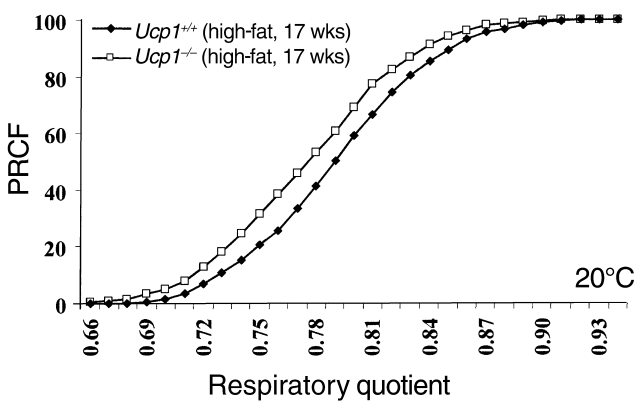

Figure 2

Plots of PRCF of RQs from 24-hour indirect-calorimetry measurements in the experiment described in Table 2. (a) Mice were fed a low-fat chow diet and then a high-fat diet. (b and $\mathbf{c}$ ) Mice were fed a high-fat diet. Each curve represents the 640 measurements of RQ from groups of eight male mice for each genotype. 
Table 3

Body temperature and physical activity of $U_{c p} 1^{-/_{-}}$and $U_{c p} 1^{+/+}$mice

\begin{tabular}{|c|c|c|c|c|}
\hline \multicolumn{5}{|c|}{ Body temperature $\left({ }^{\circ} \mathrm{C}\right)$} \\
\hline Fed & $\begin{array}{l}U_{c p 1^{+/+}} \\
U_{c p 1^{-/-}}\end{array}$ & $\begin{array}{l}37.2 \pm 0.02 \\
37.3 \pm 0.06^{A}\end{array}$ & $\begin{array}{l}37.8 \pm 0.02 \\
37.8 \pm 0.09\end{array}$ & $\begin{array}{l}36.6 \pm 0.03 \\
36.8 \pm 0.05^{\mathrm{A}}\end{array}$ \\
\hline Fasting & $\begin{array}{l}U_{c p 1^{+/+}} \\
U_{c p 1^{-/-}}\end{array}$ & $\begin{array}{l}36.2 \pm 0.10^{\mathrm{B}} \\
36.4 \pm 0.07^{\mathrm{B}}\end{array}$ & $\begin{array}{l}36.8 \pm 0.13^{B} \\
36.9 \pm 0.13^{B}\end{array}$ & $\begin{array}{l}35.6 \pm 0.09^{\mathrm{B}} \\
35.9 \pm 0.04^{\mathrm{A}},\end{array}$ \\
\hline \multicolumn{5}{|c|}{ Physical activity (count/2 min) } \\
\hline Fed & $\begin{array}{l}U_{c p 1^{+/+}} \\
U_{c p 1^{-/-}}\end{array}$ & $\begin{array}{l}5.5 \pm 0.24 \\
5.6 \pm 0.34\end{array}$ & $\begin{array}{l}8.2 \pm 0.36 \\
8.9 \pm 0.51\end{array}$ & $\begin{array}{l}2.7 \pm 0.22 \\
2.4 \pm 0.26\end{array}$ \\
\hline Fasting & $\begin{array}{l}U_{c p 1^{+/+}} \\
U_{c p 1^{-/-}}\end{array}$ & $\begin{array}{l}7.7 \pm 0.53^{\mathrm{B}} \\
8.8 \pm 1.06^{\mathrm{B}}\end{array}$ & $\begin{array}{l}10.9 \pm 0.88^{\mathrm{B}} \\
12.7 \pm 1.65^{\mathrm{B}}\end{array}$ & $\begin{array}{l}4.5 \pm 0.40^{\mathrm{B}} \\
5.0 \pm 0.56^{\mathrm{B}}\end{array}$ \\
\hline
\end{tabular}

Core body temperature and physical activity were measured in $U_{c p} 1^{-/-}$and $\mathrm{Ucp}^{1^{+/+}}$mice under fed and fasting conditions at $20^{\circ} \mathrm{C}$ by telemetry with VitalView Data Acquisition System. The determinations of body temperature and activity $(n=9-10$ mice) are averaged over the entire 24 hours and shown for the dark and light phases separately. ASignificant difference at $P<0.05$ between $U c p 1^{+/+}$and $U c p 1^{-/-}$mice; ${ }^{B}$ significant difference at $P<0.05$ between fed and fasting conditions within the same genotype.

mice is not dependent on the ambient temperature of the mice but reflects a basic difference in substrate utilization that is dependent on the fat content of the diet.

Body temperature and physical activity. As measured by the Mini Mitter Co. telemetry system, $U c p 1^{+/+}$and $U c p 1^{-/-}$fasted mice had significantly lower body temperature and higher physical activity than fed mice when the chambers were maintained at $20^{\circ} \mathrm{C}$ (Table 3 ). In addition, body temperatures of $U c p 1^{-/-}$mice were about $0.1-0.3{ }^{\circ} \mathrm{C}$ higher than those of wild-type mice. Physical activity was indistinguishable between $U c p 1^{-/-}$ and wild-type controls (Table 3 ). If $U c p 1^{-/-}$mice had increased shivering, it did not reduce physical activity. However, it is possible that a subliminal increase in shivering would not have resulted in a reduction in physical activity detectable by telemetry. A caveat to using telemetry to evaluate differences in physical activity is that telemetry can assess only whether or not a mouse moved, not differences in the extent of a movement, that is, whether the mouse moved an inch or a foot.

Metabolite analysis. UCP1-independent mechanisms for maintaining body temperature in $U c p 1^{-/-}$did not result in significant differences in energy expenditure or physical activity. A small reduction in RQ was detected and body temperature showed a slight increase in $U c p 1^{-/-}$mice. To test further the hypothesis that thermogenesis in $U c p 1^{-/-}$is more costly and results in reduced adiposity, we determined blood-metabolite levels in 2-monthold mice fed a chow diet at $27^{\circ} \mathrm{C}$ and 6-month-old mice fed a high-fat diet at $20^{\circ} \mathrm{C}$ for 4 months. The levels of $\beta$-hydroxybutyrate were significantly higher in the UCP1-deficient mice, whether the mice were fed or fasted, consistent with a higher fat oxidation

\section{Table 4} $\cup c p 1^{+/+}$mice in these animals (Table 4). In addition, FFA and triglyceride levels were generally reduced in the UCP1-deficient mice, also suggesting increased fatty acid utilization in these mice. In this experiment with congenic mice (Table 4), there was no significant hyperglycemia detected in the wild-type mice, even though it is well established that B6 mice develop diabetes when fed this high-fat diet (20). Since this high-fat feeding experiment was conducted at reduced temperature, the increased energy expenditure to maintain body temperature probably reduced hyperglycemia, as previously described for rats fed a high-fat diet (21).

At the completion of the experiment described in Table 2, following measurements of indirect calorimetry on mice fed a high-fat diet and maintained at $20^{\circ} \mathrm{C}$ for 2 weeks, mice were sacrificed and blood collected for the analysis of serum thyroid hormones and $\beta$-hydroxybutyrate levels. Similar to previous determinations (Table 4), $\beta$-hydroxybutyrate levels were elevated in the UCP1-deficient mice, suggesting increased fat oxidation in the UCP1-deficient mice (Table 5). Levels of T3 were increased in UCP1-deficient mice and those of T4 were decreased, although this was statistically significant only for $\mathrm{T} 4$. These changes in $\mathrm{T} 3$ and $\mathrm{T} 4$ are consistent with increased thyroid hormone function in these mice (Table 5).

Effects of UCP1 deficiency in white fat depots. Histological analysis of selected tissues was performed to assess the development of lipotrophy in liver and muscle and changes in fat-cell size in mice. Two-month-old $U c p 1^{-/-}$ mice fed the standard laboratory chow and kept at $27^{\circ} \mathrm{C}$ showed no changes in morphology in any of the tissues. After 8 weeks on a high-fat diet at an ambient temperature of $20^{\circ} \mathrm{C}$, no changes in morphology were detected in liver or muscle or in the epididymal or retroperitoneal fat depots; however, the inguinal fat depots of UCP1-deficient mice showed a huge increase in the number of cells with the morphology of brown adipocytes (Figure 3). This change occurred in UCP1deficient mice on both the 129 and the $\mathrm{B} 6$ genetic back-

Blood glucose, plasma triglycerides, FFA, and $\beta$-hydroxybutyrate levels of $U c p 1^{-/-}$and

\begin{tabular}{|c|c|c|c|c|c|}
\hline & & $\begin{array}{l}\text { Blood glucose } \\
(\mathrm{mg} / \mathrm{dl})\end{array}$ & $\begin{array}{c}\text { TG } \\
(\mathrm{mg} / \mathrm{dl})\end{array}$ & $\begin{array}{l}\text { FFA } \\
(\mu \mathrm{M})\end{array}$ & $\begin{array}{c}\beta \text {-Hydroxybutyrate } \\
(\mu \mathrm{M})\end{array}$ \\
\hline \multicolumn{6}{|c|}{ Chow diet ( 2 months old, $\left.27^{\circ} \mathrm{C}\right)$} \\
\hline \multirow[t]{2}{*}{ Fed } & $U c p 1^{+/+}$ & $107 \pm 2.8$ & $60 \pm 10.3$ & $417 \pm 18.8$ & $83.8 \pm 10.5$ \\
\hline & Ucp $1^{-/-}$ & $112 \pm 4.4$ & $56 \pm 5.2$ & $375 \pm 24.1$ & $141 \pm 16.6^{\mathrm{A}}$ \\
\hline \multirow[t]{2}{*}{ Fasting } & $U_{c p} 1^{+/+}$ & $63 \pm 1.6^{B}$ & NA & $1,176 \pm 119^{\mathrm{B}}$ & $1,320 \pm 67.1^{B}$ \\
\hline & $U_{c p} 1^{-/-}$ & $62 \pm 3.4^{B}$ & NA & $705 \pm 80.2^{\mathrm{A}, \mathrm{B}}$ & $1,414 \pm 110^{B}$ \\
\hline \multicolumn{6}{|c|}{ High-fat diet ( 6 months old, $\left.20^{\circ} \mathrm{C}\right)$} \\
\hline \multirow[t]{2}{*}{ Fed } & $U c p 1^{+/+}$ & $92 \pm 3.8$ & $48 \pm 9.6$ & $941 \pm 50.2$ & $133 \pm 13.6$ \\
\hline & $U_{c p} 1^{-/-}$ & $105 \pm 3.4^{\mathrm{A}}$ & $25 \pm 2.7^{\mathrm{A}}$ & $556 \pm 27.4^{\mathrm{A}}$ & $229 \pm 19.6^{A}$ \\
\hline \multirow[t]{2}{*}{ Fasting } & $U c p 1^{+/+}$ & $109 \pm 6.1$ & NA & $631 \pm 35.2^{\mathrm{B}}$ & $636 \pm 57.7^{\mathrm{B}}$ \\
\hline & Ucp $1^{-/-}$ & $102 \pm 3.6$ & NA & $796 \pm 33.4^{\mathrm{A}, \mathrm{B}}$ & $947 \pm 55.1^{A, B}$ \\
\hline
\end{tabular}

The mice fed a high-fat diet were housed at $20^{\circ} \mathrm{C}$ for 8 weeks. $n=8-10$ mice in each group. ${ }^{\text {ASig- }}$ nificant difference at $P<0.05$ between $U_{c p} 1^{+/+}$and $U_{c p} 1^{-/-}$mice; ${ }^{B}$ significant difference at $P<0.05$ between fed and fasted conditions within the same genotype. 
Table 5

Serum T3, T4, and $\beta$-hydroxybutyrate levels in $U_{c p} 1^{-/_{-}}$and $U c p 1^{+/+}$mice

\begin{tabular}{lcc}
\hline & $U c p 1^{+/+}$ & $U c p 1^{-/-}$ \\
$\mathrm{T} 3(\mathrm{ng} / \mathrm{dl})$ & $222 \pm 22$ & $237 \pm 15$ \\
$\mathrm{~T} 4(\mu \mathrm{g} / \mathrm{dl})$ & $3.4 \pm 0.3$ & $2.6 \pm 0.2^{\mathrm{A}}$ \\
$\beta$-Hydroxybutyrate $(\mu \mathrm{M})$ & $216 \pm 27$ & $392 \pm 65^{\mathrm{A}}$
\end{tabular}

Two-month-old male mice, reared at $27^{\circ} \mathrm{C}$, were singly housed and fed a highfat diet. After 2 weeks, mice were transferred to $20^{\circ} \mathrm{C}$. Two weeks later, they were sacrificed, and serum T3, T4, and $\beta$-hydroxybutyrate levels were determined. $n=7-8$ mice in each group. ASignificant differences between $U_{c p} 1^{+/+}$ and $U_{c p} 1^{-/-}$at $P<0.05$.

grounds, fed either a high-fat or low-fat diet. The increase in the number of brown adipocytes in inguinal fat did not occur in mice maintained at $27^{\circ} \mathrm{C}$.

To characterize the inguinal fat further for its brown adipocyte character, we measured the level of mRNA for the type II $5^{\prime}$-T4 deiodinase $\left(5^{\prime}\right.$-D-II), which is induced in brown adipocytes by cold exposure $(22,23)$, but not in white adipocytes, and can be used as a marker for brown adipocytes in lieu of UCP1. The interscapular brown fat of UCP1-deficient mice showed a highly significant elevation of 5'-D-II mRNA compared with that of the wild-type mice at the start of the highfat feeding (Figure 4a) and after 8 weeks of feeding at $20^{\circ} \mathrm{C}$ (Figure $4 \mathrm{~b}$ ). A very slight increase in $5^{\prime}$-D-II was detected in the inguinal fat depots of the UCP1-deficient mice at 2 months of age (Figure 4a); however, a very large increase occurred in these mice after 8 weeks on a high-fat diet at $20^{\circ} \mathrm{C}$ (Figure 4b). The level of $5^{\prime}$-D-II mRNA in the inguinal fat of UCP1-deficient mice was almost equal to the level of mRNA detected in brown fat of wild-type mice at the same age.

The basis of this difference in response among fat depots is not known, but possible mechanisms to consider include the following: (a) Increased sympathetic stimulation of the inguinal fat of UCP1-deficient mice, but not, inexplicably, of their interperitoneal fat depots. (b) The pathway for stimulation of brown adipocyte formation in white fat depots of mice is less responsive to adrenergic signaling in retroperitoneal and epididymal fat than in inguinal fat (10). (c) The precursor-cell population that gives rise to brown adipocytes, whether it consists of mature-looking white adipocytes primed to convert to brown adipocytes or of preadipocytes dedicated to the brown adipocyte lineage, is more abundant in inguinal fat than it is in epididymal or retroperitoneal fat. However, irrespective of the mechanisms, the key functional question arising from these observations is whether the increase in the number of brown adipocytes in white fat depots stimulates UCP1-independent thermogenesis.

\section{Discussion}

It was expected that UCP1-deficient mice would have increased susceptibility to obesity caused by a high-fat adipogenic diet. The reasons for this expectation followed from the considerable body of evidence show- ing that increases in brown adipocyte number and ectopic Ucp1 expression reduce excessive adiposity (reviewed in ref. 24). On the contrary, UCP1-deficient mice are resistant to the development of obesity in a manner similar to that of transgenic mice overexpressing Ucp1. That the mechanism causing the reduction in adiposity is principally thermogenic is evident from the fact that the differences in adiposity vanish when the mice are not challenged thermogenically (Figure 1). Furthermore, when the temperature is elevated, both wild-type and UCP1-deficient mice increase adiposity at the same rate, illustrating that the decreased rate of weight gain at the lower temperature was due to nonshivering thermogenesis.

We hypothesize that UCP1-deficient mice use alternative mechanisms of thermogenesis to maintain body temperature that are less efficient in the production and distribution of heat than is UCP1-mediated nonshivering thermogenesis. By expecting UCP1-deficient mice to have increased susceptibility to obesity, we have failed to appreciate that brown fat in the mouse and rat is extraordinarily efficient at generating heat $(25,26)$. First, this thermogenic uncoupling mechanism directly harnesses the energy of respiration without the intermediary production of ATP. The sympathetic nervous system rapidly and reversibly regulates respiration at the metabolic level by controlling the availability of fatty acids for oxidation by the mitochondria. Accumulated FFAs can then activate UCP1 in the inner mitochondrial membrane. In addition, the capacity of the system is rapidly upregulated by induction of Ucp1 transcription by adrenergic signaling. These same adrenergic signals also stimulate blood

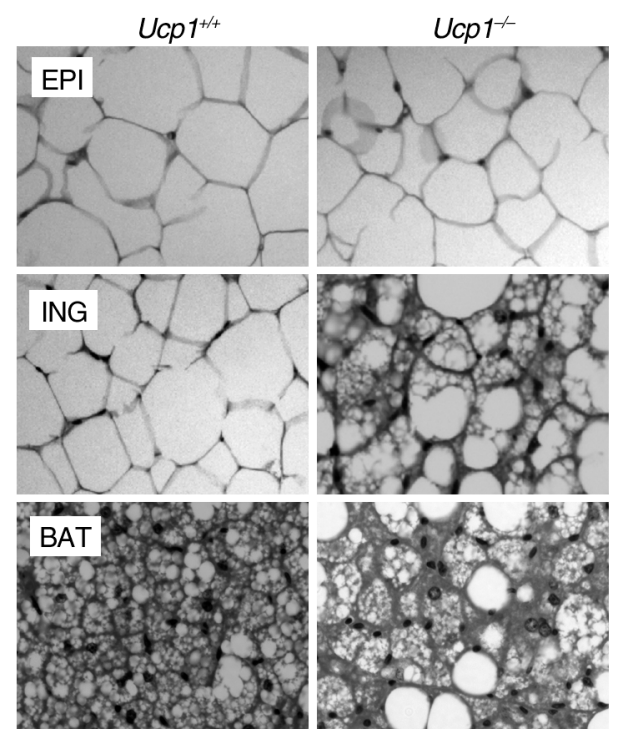

\section{Figure 3}

Comparison of the histology of fat pads from $U c p 1^{+/+}$and $U c p 1^{-/-}$ mice, showing the selective induction of brown adipocytes in the inguinal fat depot of $U_{c p} 1^{-/-}$mice. Histological sections were stained with H\&E. EPI, epididymal fat; ING, inguinal fat; BAT, brown adipose tissue. 


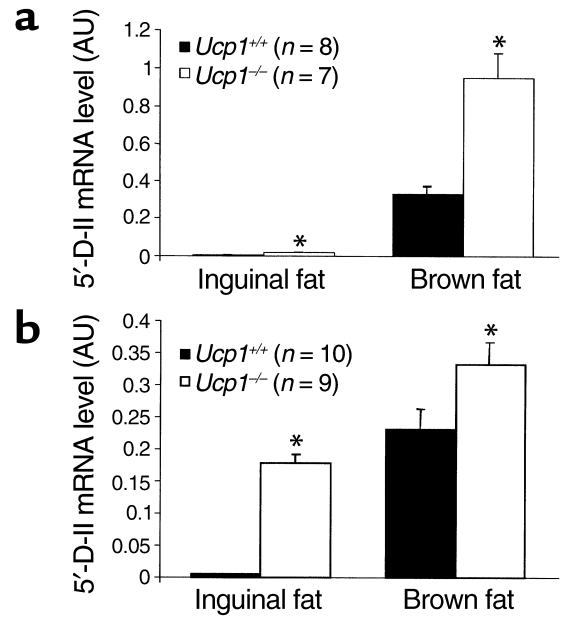

Figure 4

Levels of $5^{\prime}$-D-II mRNA in inguinal and brown fat of $U_{c p} 1^{-/-}$mice (white bars) compared with wild-type mice (black bars). (a) Twomonth-old mice fed standard chow at $27^{\circ} \mathrm{C}$. (b) Six-month-old mice fed a high-fat, high-sucrose diet for 8 weeks at $20^{\circ} \mathrm{C} .{ }^{*} P<0.05$. $\mathrm{AU}$, arbitrary units.

flow through brown fat to quickly and efficiently distribute heat to vital organs.

In the absence of this finely tuned reversible thermogenic mechanism, the animal must rely on various forms of substrate cycling that depend on ATP synthesis and breakdown. Candidate cycling mechanisms are: 1) relaxation and contraction of muscle during shivering; 2) turnover of macromolecules, including proteins, glycogen, and triglycerides; 3) ATPase-dependent ion fluxes across membranes and 4) heat able to be derived from the diminished yield of ATP from oxidation of glycerol phosphate by the mitochondrial glycerol phosphate dehydrogenase (27). These alternative mechanisms may not be subject to the same stringent level of regulation as brown fat thermogenesis for the conservation of energy. In fact, in the mouse, as evidenced by the sensitivity of UCP1-deficient mice to the cold (4), they have not been designed to function as an effective defense against the cold.

The alternative mechanisms of thermogenesis that are used in UCP1-deficient mice have not yet been identified. Our strongest clues for the nature of alternative mechanisms come from evidence for increased thyroid function in $U c p 1^{-/-}$mice. Activity of $5^{\prime}$-D-II is elevated in both interscapular brown fat and the inguinal fat depot, resulting in an increase in the $\mathrm{T} 3 / \mathrm{T} 4$ ratio in the blood. Three thyroid hormone-responsive alternative thermogenic mechanisms are muscle UCP3 (28), the glycerol phosphate cycle (29), and the muscle sarcoplasmic reticulum $\mathrm{Ca}^{++}$-ATPase (30). We have previously shown that there is a $50 \%$ increase in the level of mitochondrial glycerol-3-phosphate dehydrogenase $(\mathrm{mGPDH})$ in interscapular fat of $U c p 1^{-/-}$mice (19). The mGPDH and the cytoplasmic GPDH have been proposed to form a thermogenic substrate cycle that dissipates energy and regulates body weight (31). The addi- tional induction of brown adipocytes in the inguinal fat depots of UCP1-deficient mice would further increase the capacity of the glycerol phosphate cycle. Mice with the wild-type Ucp 1 gene that carry inactive cytoplasmic or mitochondrial GPDH genes do not show increased sensitivity to the cold $(32,33)$; howev$\mathrm{er}$, in the absence of UCP1, the glycerol phosphate cycle could play a larger role in overall thermogenesis.

In a similar manner, UCP3 is not induced in UCP1deficient mice (34) and, therefore, was not able to compensate for UCP1 deficiency to protect the mice from the cold; nevertheless, it could also be part of a generalized stimulation of thermogenesis by thyroid hormone. $\mathrm{UCP} 2$ is also a potential alternative mechanism of thermogenesis, but like UCP3, it is not able to compensate for loss of UCP1 by protecting the mouse from the cold, despite the elevated levels of $U c p 2$ mRNA in brown fat of UCP1-deficient mice (4). Because mice with inactivated genes for $U c p 2$ and $U c p 3$ are not sensitive to the cold like Ucp1-targeted mice $(35,36)$, there has been a tendency to conclude that UCP2 and UCP3 are not thermogenic. A criterion for a thermogenic function, as exemplified by the cold-sensitivity characteristic of UCP1-deficient mice, may be too stringent for other mechanisms of thermogenesis. Inability to substitute for UCP1 to protect the mouse from the cold or generate a cold-sensitive phenotype does not exclude the possibility that, in another physiological context, one of the alternative mechanisms cited herein may serve an important thermogenic function. This leads to the caveat that the evaluation of any potential mechanism of thermogenesis should be conducted in UCP1-deficient mice with experiments that are capable of detecting subtle changes in phenotype.

Finally, a third thyroid hormone-inducible mechanism is the sarcoplasmic reticulum $\mathrm{Ca}^{++}$-ATPase, which plays a vital role in shivering thermogenesis as part of the contraction-relaxation process of muscle. The induction or utilization of thermogenic mechanisms involving the sarcoplasmic reticulum $\mathrm{Ca}^{++}$-ATPases, which function outside of mechanisms for muscle contraction as described for heater organs in fish (37), has been proposed as a mechanism for nonshivering thermogenesis in humans (38), and it is certainly worth evaluating in UCP1-deficient mice.

Recently, Golozoubova et al. (39) proposed in a study of UCP1-deficient mice that shivering was the only alternative to adaptive nonshivering thermogenesis. It is quite certain that shivering thermogenesis is a major contributing thermogenic mechanism in UCP1-deficient mice. However, before we can conclude that shivering alone accounts for adaptive thermogenesis in the absence of UCP1, it is necessary to account for the following phenotypic characteristics of UCP1-deficient mice. First, selective congenic strains of UCP1-deficient mice, and even those on an undefined genetic background, require adaptation by a slow reduction of the ambient temperature over a 2 -week period before they can tolerate $4^{\circ} \mathrm{C}$ cold (our unpublished results, and ref. 
39). This indicates that the shivering capacity of a mouse acutely exposed to the cold cannot maintain body temperature, and that either an enhanced capacity for shivering or a nonshivering mechanism must be induced. If shivering is induced, then changes in muscle physiology should be evident, in a manner similar to muscle training.

At present there is no evidence showing that shivering is either quantitatively or qualitatively different following adaptation. Furthermore, the experiments of Golozoubova et al. (39) show that the electromyographs of shivering in UCP1-deficient mice maintained at thermoneutrality are quantitatively and qualitatively indistinguishable from those of shivering in mice adapted to tolerate the cold. What, then, is the molecular basis of a physiological adaptation to cold that required a 3-week exposure to $18^{\circ} \mathrm{C}$ ? Second, while UCP1-deficient congenic mice on either a B6 or a 129 background are extremely sensitive to the cold, the deficient mice on a $(\mathrm{B} 6 \times 129) \mathrm{F}_{1}$ background are resistant to the cold (19) without any adaptation. This phenomenon, called heterosis, indicates that a compensatory mechanism to protect mice against the cold is constitutively present in mice on a hybrid background even when they are maintained at $29^{\circ} \mathrm{C}$. Accordingly, the existence of both adaptive and constitutive thermogenesis in the UCP1-deficient mice suggests that alternative mechanisms for thermogenesis exist. These alternative mechanisms of thermogenesis in UCP1deficient mice may be novel; however, the characteristics of shivering, and its capacity for genetic and environmental variability, may be much richer than previously appreciated.

It is generally believed that the adult human is virtually UCP1-deficient, and that, under basal conditions, nonshivering thermogenesis is not an important mechanism for the control of human body weight (40, 41). Exactly how accurate this assessment is for a role of the brown adipocyte in body weight regulation is still uncertain. Independent of the question of the role of UCP1 in body weight regulation in adult humans, much remains to be discovered about mechanisms of thermogenesis that participate in determining the range of susceptibility to obesity in the human population. Since differences in susceptibility to obesity occur even when the levels of food intake and physical activity are similar, individual differences in metabolic efficiency and thermogenesis probably are determinants of increased susceptibility to obesity. It is possible that the UCP1-deficient mouse will provide a useful genetic model to elucidate UCP1-independent mechanisms of thermogenesis. The increased resistance of UCP1-deficient mice to diet-induced obesity occurring in the context of increased fat oxidation is consistent with well-documented observations showing that resistance to obesity in humans also occurs in those individuals with an enhanced capacity for fat oxidation $(42,43)$. The elevated levels of $\beta$-hydroxybutyrate in young UCP1-deficient mice on a chow diet suggest that increased fat oxidation in these mice is a constitutive trait that becomes most evident in mice fed a high-fat diet (Table 4 and Figure 2). The reduced $\mathrm{RQ}$ in postobese individuals compared with those who were never obese suggests that variation in fat oxidation in humans may also be a constitutive trait that affects susceptibility to obesity (44). It is important to determine whether this characteristic of fat oxidation in humans is a genetically determined trait or a consequence of the environment. There is evidence for reductions in the levels of enzymes of lipid oxidation in the muscles of obese humans (45). In addition, leptin has been implicated in the activation of pathways for lipid oxidation in adenovirus-induced hyperleptinemia (46) and in muscle by the AMP-kinase pathway (47). It is also clear from the analysis of mice with an inactivated gene for PPAR $\alpha$ that this transcription factor is important in activation of enzymes of lipid oxidation in liver. Obesity-resistant UCP1-deficient mice do not have increased levels of PPAR $\alpha$ mRNA in liver (our unpublished observations).

In summary, the UCP1-deficient mouse provides a model in which there is an increased resistance to obesity due to the inactivation of a major thermogenic mechanism. We interpret this to indicate that alternative UCP1-independent mechanisms required to regulate body temperature are more costly energetically and result in an increased expenditure of energy. Accordingly, this mouse provides a new model to investigate alternative mechanisms of thermogenesis and their relationship to the regulation of body weight.

\section{Acknowledgments}

We thank Eric Ravussin and Robert Koza for discussions throughout the course of this work and for reviewing the manuscript. We thank Christie Bearden for her dedicated efforts in maintaining the mouse colony. This research was supported by grant HD08431 from the NIH and an award from Pfizer Inc.

1. Rothwell, N.J., and Stock, M.J. 1979. A role for brown adipose tissue in diet-induced thermogenesis. Nature. 281:31-35.

2. Rothwell, N.J., and Stock, M.J. 1983. Acute effects of fat and carbohydrate on metabolic rate in normal, cold-acclimated and lean and obese (fa/fa) Zucker rats. Metabolism. 32:371-376.

3. Rippe, C., Berger, K., Boiers, C., Ricquier, D., and Erlanson-Albertsson, C. 2000. Effect of high-fat diet, surrounding temperature, and enterostatin on uncoupling protein gene expression. Am. J. Physiol. Endocrinol. Metab. 279:E293-E300.

4. Enerback, S., et al. 1997. Mice lacking mitochondrial uncoupling protein are cold-sensitive but not obese. Nature. 387:90-94.

5. Matthias, A., et al. 2000. Thermogenic responses in brown fat cells are fully UCP1-dependent. UCP2 or UCP3 do not substitute for UCP1 in adrenergically or fatty acid-induced thermogenesis. J. Biol. Chem. 275:25073-25081.

6. Kopecky, J., Clarke, G., Enerback, S., Spiegelman, B., and Kozak, L.P. 1995. Expression of the mitochondrial uncoupling protein gene from the aP2 gene promoter prevents genetic obesity. J. Clin. Invest. 96:2914-2923.

7. Kopecky, J., Hodny, Z., Rossmeisl, M., Syrovy, I., and Kozak, L.P. 1996. Reduction of dietary obesity in aP2-Ucp transgenic mice: physiology and adipose tissue distribution. Am. J. Physiol. 270:E768-E775.

8. Cummings, D.E., et al. 1996. Genetically lean mice result from targeted disruption of the RII beta subunit of protein kinase A. Nature. 382:622-626.

9. Li, B., et al. 2000. Skeletal muscle respiratory uncoupling prevents dietinduced obesity and insulin resistance in mice. Nat. Med. 6:1115-1120. 
10. Guerra, C., Koza, R.A., Yamashita, H., Walsh, K., and Kozak, L.P. 1998. Emergence of brown adipocytes in white fat in mice is under genetic control. Effects on body weight and adiposity. J. Clin. Invest. 102:412-420.

11. Himms-Hagen, J., et al. 1994. Effect of CL-316,243, a thermogenic beta 3 -agonist, on energy balance and brown and white adipose tissues in rats. Am. J. Physiol. 266:R1371-R1382.

12. Cederberg, A., et al. 2001. FOXC2 is a winged helix gene that counteracts obesity, hypertriglceridemia, and diet-induced insulin resistance. Cell. 106:563-573.

13. Lowell, B.B., et al. 1993. Development of obesity in transgenic mice after genetic ablation of brown adipose tissue. Nature. 366:740-742.

14. Hamann, A., Flier, J.S., and Lowell, B.B. 1996. Decreased brown fat markedly enhances susceptibility to diet-induced obesity, diabetes, and hyperlipidemia. Endocrinology. 137:21-29.

15. Mantzoros, C.S., et al. 1998. Severe leptin resistance in brown fat-deficient uncoupling protein promoter-driven diphtheria toxin A mice despite suppression of hypothalamic neuropeptide $\mathrm{Y}$ and circulating corticosterone concentations. Diabetes. 47:230-238.

16. Stefl, B., et al. 1998. Brown fat is essential for cold-induced thermogenesis but not for obesity resistance in aP2-Ucp mice. Am. J. Physiol. 274:E527-E533.

17. Surwit, R.S., Kuhn, C.M., Cochrane, C., McCubbin, J.A., and Feinglos, M.N. 1988. Diet-induced type II diabetes in C57BL/6J mice. Diabetes. 37:1163-1167.

18. Bachmanov, A.A., Reed, D.R., Tordoff, M.G., Price, R.A., and Beauchamp, G.K. 2001. Nutrient preference and diet-induced adiposity in C57BL/6ByJ and 129P3/J mice. Physiol. Behav. 72:603-613.

19. Hofmann, W.E., Liu, X., Bearden, C.M., Harper, M.E., and Kozak, L.P. 2001. Effects of genetic background on thermoregulation and fatty acidinduced uncoupling of mitochondria in UCP1-deficient mice. J. Biol. Chem. 276:12460-12465.

20. Surwit, R.S., Seldin, M.F., Kuhn, C.M., Cochrane, C., and Feinglos, M.N. 1991. Control of expression of insulin resistance and hyperglycemia by different genetic factors in diabetic C57BL/6J mice. Diabetes. 40:82-87.

21. Vallerand, A.L., Lupien, J., and Bukowiecki, L.J. 1986. Cold exposure reverses the diabetogenic effects of high-fat feeding. Diabetes. 35:329-334.

22. Croteau, W., Davey, J.C., Galton, V.A., and St. Germain, D.L. 1996. Cloning of the mammalian type II deiodinase. A selenoproetin differentially expressed and regulated in human and rat brain and other tissues. J. Clin. Invest. 98:405-417.

23. Guerra, C., et al. 1998. Abnormal nonshivering thermogenesis in mice with inherited defects of fatty acid oxidation. J. Clin. Invest. 102:1724-1731.

24. Kozak, L.P., and Harper, M.-E. 2000. Mitochondrial uncoupling proteins in energy expenditure. Annu. Rev. Nutr. 20:339-363.

25. Nicholls, D.G., and Locke, R.M. 1984. Thermogenic mechanisms in brown fat. Physiol. Rev. 64:1-64.

26. Himms-Hagen, J., and Ricquier, D. 1998. Brown adipose tissue. In Hand book of obesity. G.A. Bray, C. Bouchard, and W.P.T. James, editors. Marcel Dekker Inc. New York, New York, USA. 415-441.

27. Newsholme, E.A., and Stanley, J.C. 1987. Substrate cycles: their role in control of metabolism with specific references to liver. Diabetes Metab. Rev. 3:295-305.

28. Gong, D.W., He, Y., Karas, M., and Reitman, M. 1997. Uncoupling pro- tein-3 is a mediator of thermogenesis regulated by thyroid hormone, beta3-adrenergic agonists, and leptin. J. Biol. Chem. 272:24129-24132.

29. Lee, Y.-P., and Lardy, H.A. 1965. Influence of thyroid hormones on L-aglycerophosphate dehydrogenases and other dehydrogenases in various organs of the rat. J. Biol. Chem. 240:1427-1436.

30. Simonides, W.S., van der Linden, G.C., and van Hardeveld, C. 1990. Thyroid hormone differentially affects mRNA levels of Ca-ATPase isozymes of sarcoplasmic reticulum in fast and slow skeletal muscle. FEBS Lett. 274:73-76

31. Lardy, H., and Shrago, E. 1990. Biochemical aspects of obesity. Annu. Rev. Biochem. 59:689-710.

32. Prochazka, M., Kozak, U.C., and Kozak, L.P. 1989. A glycerol-3-phosphate dehydrogenase null mutant in BALB/cHeA mice. J. Biol. Chem. 264:4679-4683.

33. Brown, L.J., et al. 2002. Normal thyroid thermogenesis but reduced viability and adiposity in mice lacking the mitochondrial glycerol phosphate dehydrogenase. J. Biol. Chem. 277:32892-32898.

34. Monemdjou, S., Hofmann, W.E., Kozak, L.P., and Harper, M.E. 2000. Increased mitochondrial proton leak in skeletal muscle mitochondria of UCP1-deficient mice. Am. J. Physiol. Endocrinol. Metab. 279:E941-E946.

35. Gong, D.W., et al. 2000. Lack of obesity and normal response to fasting and thyroid hormone in mice lacking uncoupling protein-3. J. Biol. Chem. 275:16251-16257.

36. Vidal-Puig, A.J., et al. 2000. Energy metabolism in uncoupling protein 3 gene knockout mice. J. Biol. Chem. 275:16258-16266.

37. Block, B.A. 1994. Thermogenesis in muscle. Annu. Rev. Physiol. 56:535-577.

38. Simonides, W.S., Thelen, M.H., van der Linden, C.G., Muller, A., and van Hardeveld, C. 2001. Mechanism of thyroid-hormone regulated expression of the SERCA genes in skeletal muscle: implications for thermogenesis. Biosci. Rep. 21:139-154.

39. Golozoubova, V., et al. 2001. Only UCP1 can mediate adaptive nonshivering thermogenesis in the cold. FASEB J. 15:2048-2050.

40. Lean, M.E.J. 1992. Evidence for brown adipose tissue in humans. In Obesity. P. Bjorntrop and B.N. Brodoff, editors. J.B. Lippincott. Philadelphia, Pennsylvania, USA. 117-129.

41. Lowell, B.B., and Spiegelman, B.M. 2000. Towards a molecular understanding of adaptive thermogenesis. Nature. 404:652-660

42. Zurlo, F., et al. 1990. Low ratio of fat to carbohydrate oxidation as predictor of weight gain: study of 24-h RQ. Am. J. Physiol. 259:E650-E657.

43. Kelley, D.E., Goodpaster, B., Wing, R.R., and Simoneau, J.A. 1999. Skeletal muscle fatty acid metabolism in association with insulin resistance, obesity, and weight loss. Am. J. Physiol. 277:E1130-E1141.

44. Filozof, C.M., et al. 2000. Low plasma leptin concentration and low rates of fat oxidation in weight-stable post-obese subjects. Obes. Res. 8:205-210.

45. Simoneau, J.A., Veerkamp, J.H., Turcotte, L.P., and Kelley, D.E. 1999. Markers of capacity to utilize fatty acids in human skeletal muscle: relation to insulin resistance and obesity and effects of weight loss. FASEB J. 13:2051-2060.

46. Zhou, Y.-T., et al. 1997. Induction by leptin of uncoupling protein-2 and enzymes of fatty acid oxidation. Proc. Natl. Acad. Sci. USA. 94:6386-6390.

47. Minokoshi, Y., et al. 2002. Leptin stimulates fatty-acid oxidation by activating AMP-activated protein kinase. Nature. 415:339-343. 